\title{
Seismic response of cracked soil deposits
}

\author{
F. A. Flores \& J. M. Mayoral \\ Instituto de Ingeniería, Universidad Nacional Autónoma de México, \\ Mexico City, Mexico
}

\begin{abstract}
This paper examines the influence that cracks and discontinuities can have over the seismic response of a hypothetical soil profile using a bidimensional finite difference model. The soil is considered as having a bilinear behavior using a Mohr-Coulomb model. The soil openings are simulated with interface elements, where the soil stiffness is used to characterize the contact force when the crack closes. Transmitting boundaries were used at the edges and bottom of the model to allow for energy dissipation of the reflected waves. The effect of cracking in the seismic response was evaluated comparing the results of site response analysis with and without discontinuities, for several lengths and orientations. From the results of this investigation, insight was gained regarding the effect that discontinuities may have in the seismic response of soil deposits and soilstructure systems.
\end{abstract}

Keywords: cracks, interface, seismic, finite difference model.

\section{Introduction}

The presence of cracks or fissures on rigid soils, such as stiff clays or sandy silts, is generally related to particular subsoil conditions combined with external environmental phenomena such as long periods of drought or excessive water extraction from underground aquifers. These natural discontinuities may affect both the static and seismic performance of structures sitting on top of them.

In this work, the influence of cracks and discontinuities (closed cracks) in the seismic response of a hypothetical soil deposit, and a six-story building located near by the crack, is assessed using a two-dimensional finite difference model. In this paper a discontinuity is considered as a closed crack. Thus full contact exists between both edges. Therefore only compressional forces are transmitted normally to the interface from one edge to the other. The site response is 
obtained with and without open and closed cracks, considering several longitudes and orientations of the crack. Both the effect of a single crack and a family of cracks is revised.

\section{Description of numerical model}

\subsection{Dynamic aspects}

Figure 1 illustrates the model considered for the parametric study presented herein, which includes both the wave propagation analysis in the soil deposit to assess potential changes in ground response due to the presence of cracks, and the seismic soil structure interaction, SSI, analysis to revise the effect in adjacent structures.

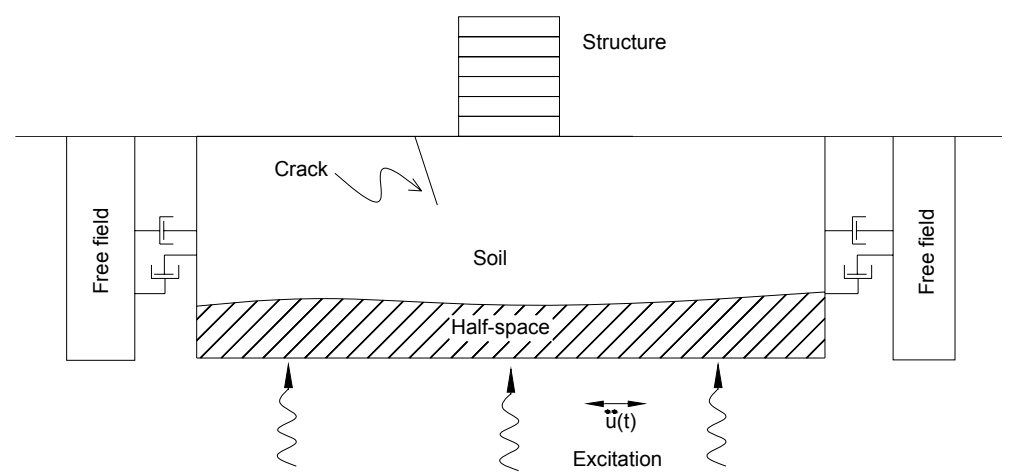

Figure 1: Schematic representation of the model for dynamic analyses.

\subsection{Discontinuities modeling}

Discontinuities or contact points that may exist between two surfaces can be represented in a model through interface elements. There are a number of interface elements similar to that depicted in Figure 2, which are able to simulate the sliding, and opening-closing mechanism, in the case of seismic response, between two contacts. Crack opening and sliding occurs once the limit tension is exceeded at the interface between two contacts in the parallel or tangential direction with respect to the discontinuity. During crack closing the interface will have an equivalent normal stiffness and will transmit normal stresses and the corresponding strains to both sides of the crack. Equivalent normal stiffness, $k_{s}$, has a direct influence on the dynamic time, required to solve the problem. The maximum $k_{s}$ value can be obtained from the following expression:

$$
k_{s}=\left[\frac{K+\frac{4}{3} G}{\Delta z_{\min }}\right]
$$


where: $\mathrm{K}$ and $\mathrm{G}$ are volumetric and shear soil modulus, respectively, and $\Delta \mathrm{z}_{\min }$ is the minimum distance from an element of the mesh in the normal direction to the interface (c.f. Figure 2).

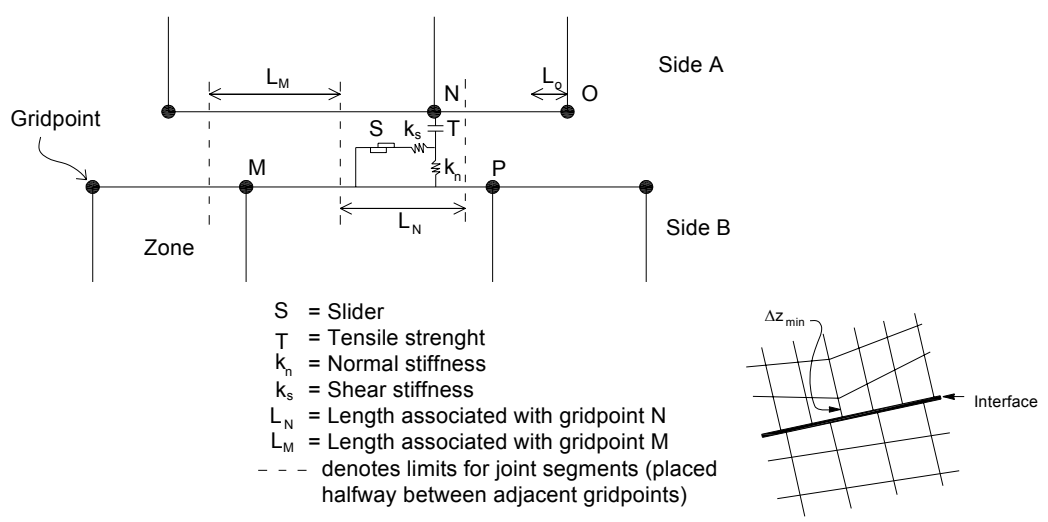

Figure 2: Representation of an interface connected to normal and shearing rigid springs and tension and slipping elements (Itasca [1]).

\section{$3 \quad$ Numerical modeling}

\subsection{Soil profile}

A typical soil deposit such as those existing at the surroundings of Aguascalientes valley, Mexico, was considered as scenario for the seismic study. An idealized soil profile of the deposit and the corresponding properties of each material are presented in Figure 3, which were modified from Rojas et al. [2].

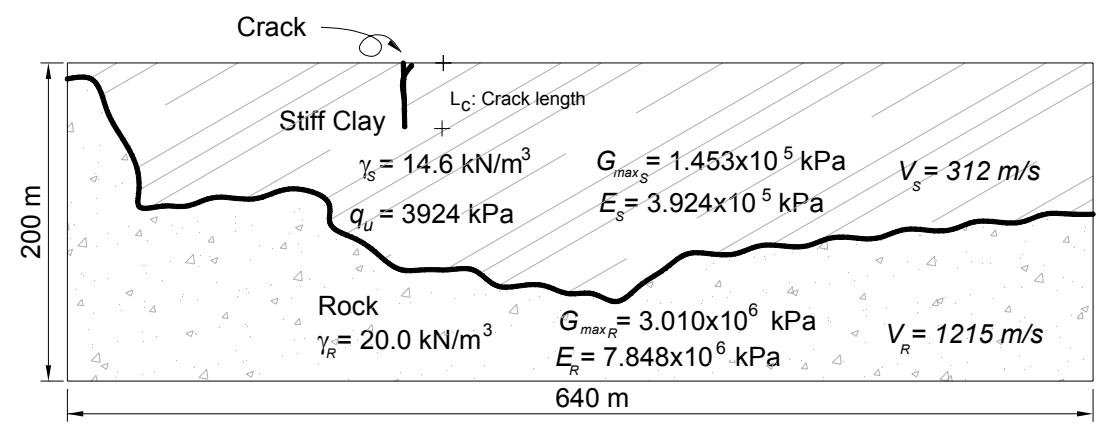

Figure 3: $\quad$ Idealized soil profile.

As can be noticed, the deposit is comprised of a very stiff clay layer resting on top of basal rock with a very irregular geometry. The dynamic impedance between both materials $\left(\mathrm{V}_{\mathrm{R}} \gamma_{\mathrm{R}}\right) /\left(\mathrm{V}_{\mathrm{s}} \gamma_{\mathrm{s}}\right)$ is about 5. It was assumed that the water 
table was below the maximum depth of the model (i.e. $200 \mathrm{~m}$ ). Figure 3 also shows the assumed crack location.

\subsection{Input motion}

Based on a survey of the available seismological information, the closest seismological station on rock, identified as TONA, is located at about $170 \mathrm{~km}$ towards the southwest of Aguascalientes State, (Figure 4). Thus, a representative strong ground motion recorded at this station was selected for the parametric study. The acceleration time history corresponding for the strong ground motion recorded at TONA station during the October 9,1995 earthquake $\left(M_{w} 7.3\right)$ is depicted in Figure 5. The seismic motion duration is 80 seconds and has a predominant period of about 2.2 seconds. This ground motion was deconvolved to the base rock using the program SHAKE (Schnabel et al. [3]).

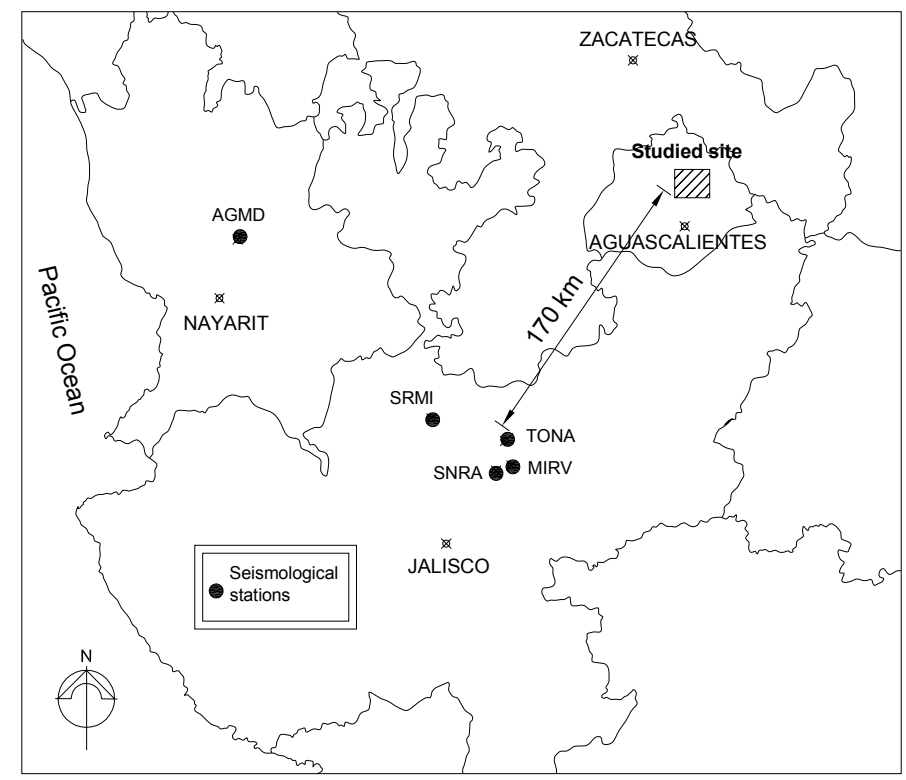

Figure 4: $\quad$ Studied site and closest stations on rock.

\subsection{Model characteristics}

The finite differences mesh used to represent the idealized soil profile is shown in Figure 6. A total of 840 quadrilateral plane elements were used in the analysis. Mesh elements are $15 \mathrm{~m}$ long and 10 high. The stress-strain relationship for soils was assumed elastic perfectly plastic with a Mohr-Coulomb failure criterion. The rock was considered as an elastic material. Transmitting boundaries were placed at the edges of the model to allow radiation energy dissipation into the surrounding media. The ground motion was applied at the base of the model 
considering a rigid base. The depth of the model below the base rock was increased until the effect of potential reflection of incoming waves from the soil to the base was minimized. Equivalent linear properties were used to take into account approximately soil nonlinearities. The normalized shear modulus degradation and damping curves proposed by Sun et al. [4] and Vucetic and Dobry, [5] respectively, were used to represent the dependency of dynamic soil properties with shear strain amplitude, for the low plasticity clays $(10<\mathrm{PI}<$ $20 \%$ ) prevailing at the site.

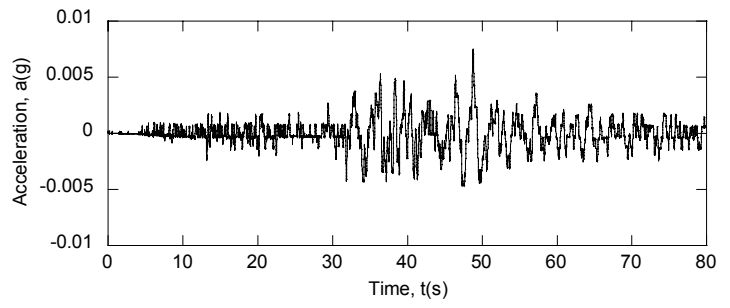

Figure 5: Acceleration time history recorded at TONA station during the October 9, 1995 earthquake (TONA9510).

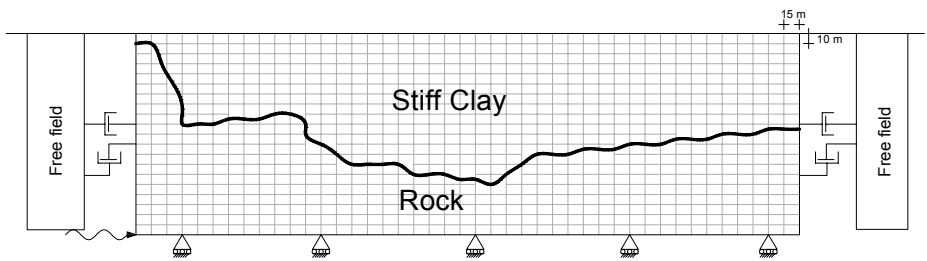

Figure 6: Finite differences mesh.

\subsection{Crack length influence}

The influence of the crack length in the seismic response of the soil deposit was evaluated assuming a closed vertical crack located at point $\mathrm{X}$, as depicted in figure 7. The closed crack implies that there is contact between both edges of the crack, thus the crack is able to transmit forces oriented perpendicularly to the discontinuity in compression but not in tension. This figure also shows the location of several stations S-1, S-2, S-3, and S-4 where the responses were obtained. The crack was assumed to be 10,20 and $40 \mathrm{~m}$ long. Figure 8 shows a comparison of the response spectra obtained at both sides of the discontinuity (points $X^{\prime}$ and $X^{\prime \prime}$ ) for the three crack lengths $(10,20$ and $40 \mathrm{~m}$ ), and the response obtained when there is not crack in the stiff clay. From these results two conclusions can be drawn. First for crack lengths, $\mathrm{L}_{\mathrm{c}}$, smaller than $20 \mathrm{~m}$, the effect of the discontinuity in the ground response is negligible, as can be deduced by the fact that none important change in frequency content nor amplitude is observed with respect those computed with no crack. Second, for $\mathrm{L}_{\mathrm{c}}$ closed to $40 \mathrm{~m}$ or longer, the response changes significantly, as can be concluded for the 
important amplification of the spectral ordinates at point $\mathrm{X}^{\prime}$. This, however, is not so notorious in the response computed al point $\mathrm{X}^{\prime \prime}$. This can be explained in terms of the fact that the basal rock is closer to the ground surface at the left side of the crack, and generates surface waves that are trapped in the left side of the discontinuity. Thus, although it is important to make appropriate considerations when designing engineering works to be located in the proximity of a crack to avoid risks resulting from an incoherent seismic response of the structure foundation, this effect appears to be relevant for quite long discontinuities. Figure 9 summarizes the effect that a crack with variable depth (10 to $40 \mathrm{~m})$ may have in the peak ground accelerations, PGA, computed along the model surface. Again, it can be observed that the only effect occurs when the crack length reaches a value of $40 \mathrm{~m}$. The maximum amplification occurs at the left side of the crack, however, it seems that the presence of the crack causes an out of face response on the ground with respect to that observed in the soil deposit when there is no crack, amplifying or attenuating the surface ground motions and being the source of potential ground motion incoherence.

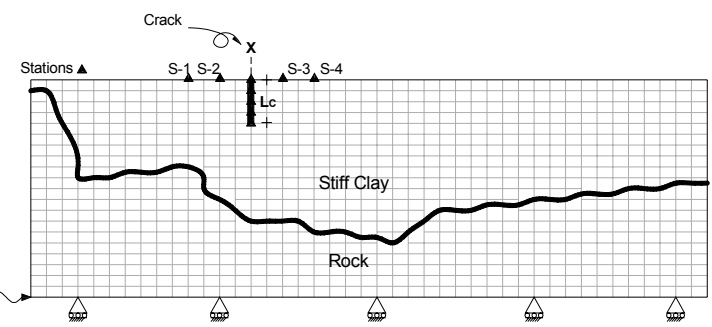

Figure 7: Crack and monitoring points location.

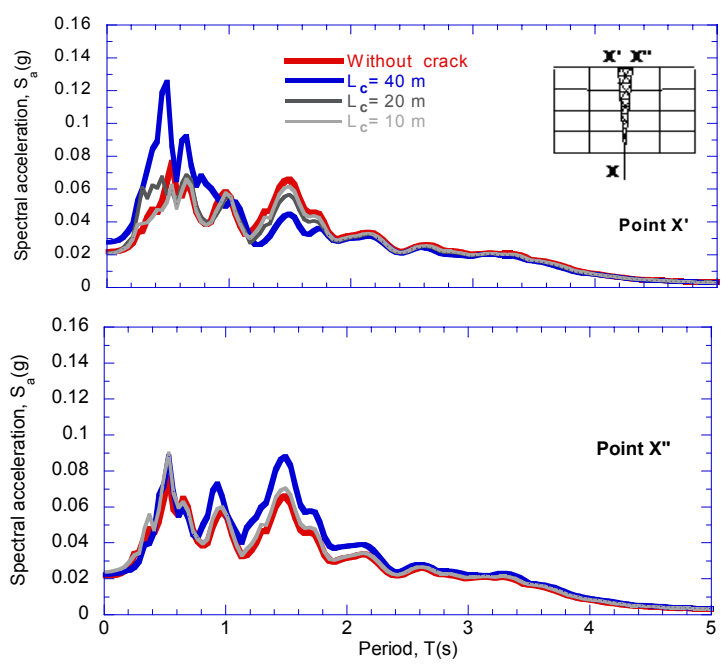

Figure 8: Response spectra for different crack lengths at both sides of the discontinuity. 


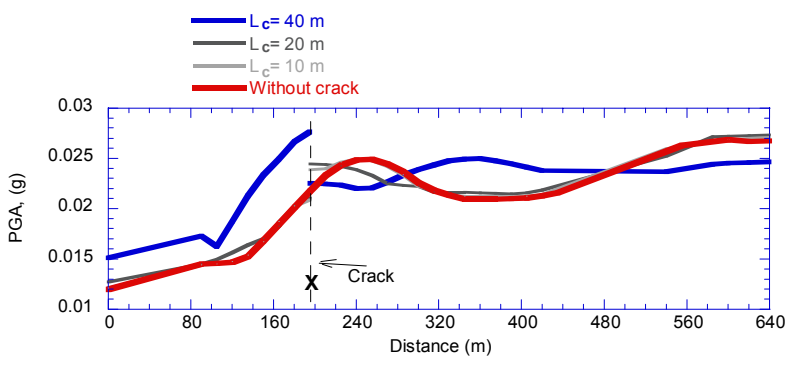

Figure 9: $\quad$ PGA distribution over the model for a crack located in X.
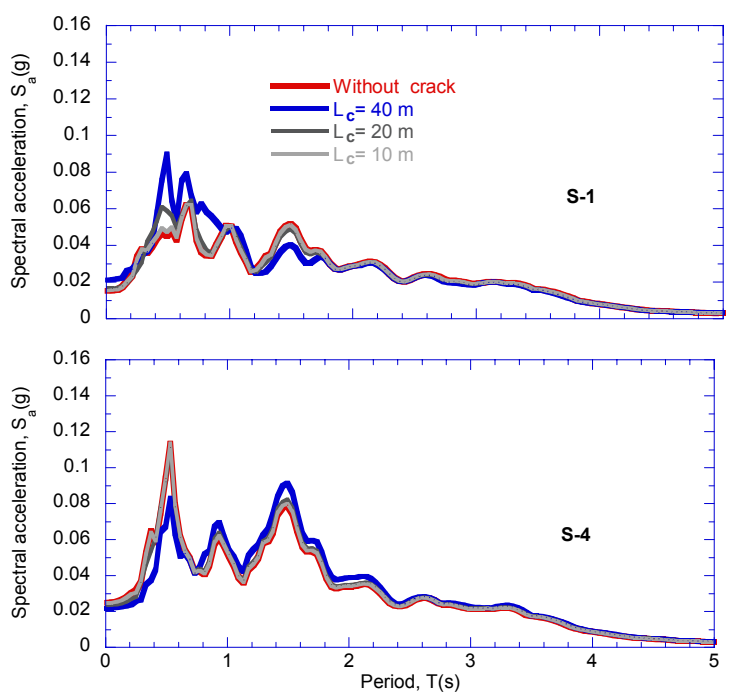

Figure 10: Dynamic effects of discontinuities in nearby points.

Figure 10 shows that the effect in frequency content is again more important in station S-1, which is located to the left of the crack, but less significant at station S-4, which is located to the right of the crack.

Regarding the effect of the crack at depth, figure 11 shows that this completely vanished for depths larger than the crack length, and the cracked media practically follows the un-cracked media motions.

\subsection{Crack inclination influence}

In this section the effect of an inclined crack is studied. A $40 \mathrm{~m}$ depth of crack with inclination, $i$, of $2.15,5,-2.15$, and -5 degrees, measured with respect to the vertical, was assumed, as schematically represented in figure 12 . This figure also shows the computed PGA's variation over the entire model. As can be noticed, for the particular case studied herein, there is practically no effect due to crack orientation, even for the largest value considered. 


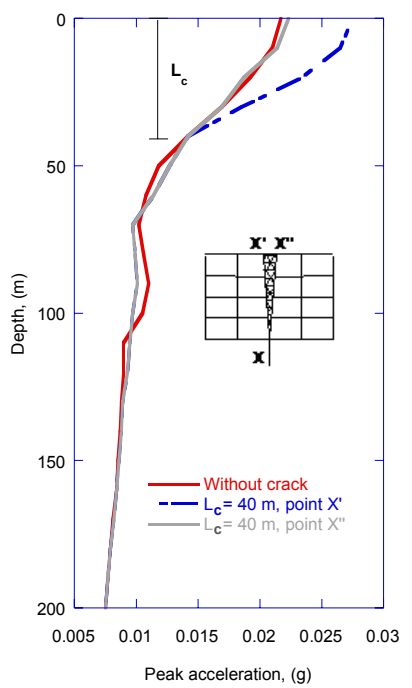

Figure 11: Influence of the crack in the peak acceleration variation with depth.

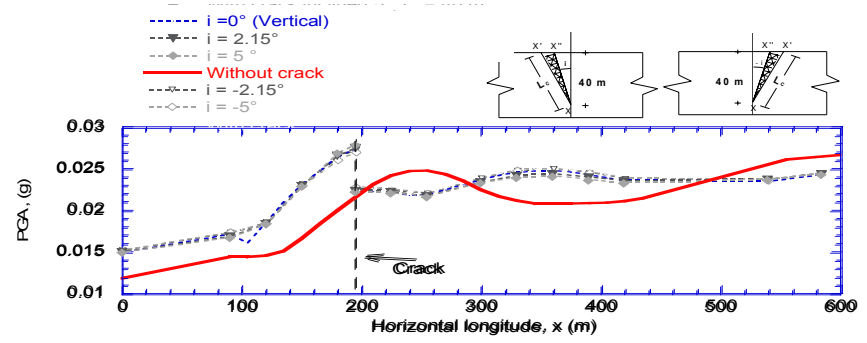

Figure 12: Peak ground accelerations distribution for several crack orientations.

\subsection{Influence of a cracks family}

The influence of three $40 \mathrm{~m}$-cracks separated $30 \mathrm{~m}$ away from each other is studied. Figure 13 presents a schematic representation of the cracks, indicating their relative position. Figure 14 presents the computed response spectra at points $\mathrm{X}^{\prime}$ and $\mathrm{X}^{\prime \prime}$ for both the single and the group of cracks. It seems that the crack group tends to reduce even further the period at which the soil is responding. This can be associated with high frequencies generated by the discontinuities. The peak spectral ordinate decreases when the crack group is considered with respect to that computed for a single crack. Figure 15 shows the corresponding PGA distribution over the model. It can be noticed a very important amplification of computed PGA for the crack family with respect to both the soil without crack and a single crack (more than 200\%). This effect should be taken into account for foundation design to avoid damage of structures, in particular if they are stiff. 


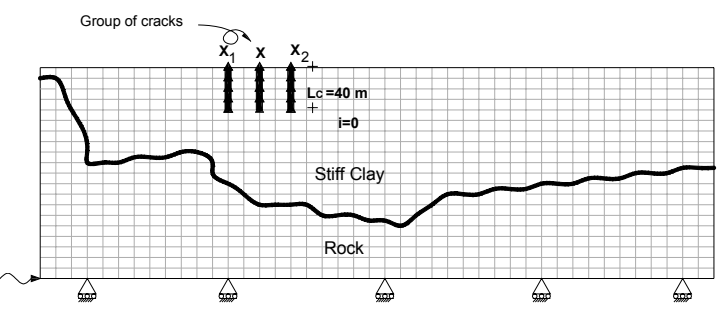

Figure 13: Control nodes for influence of a cracks family.

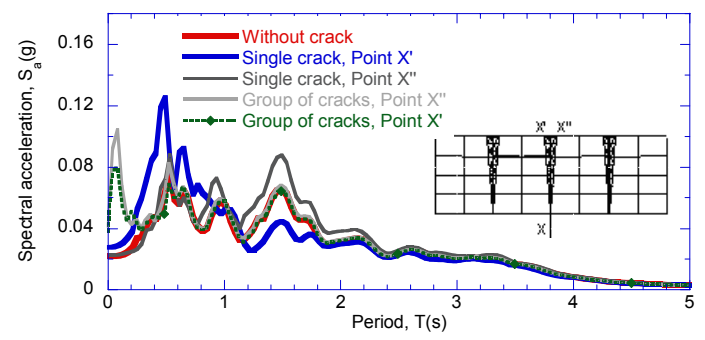

Figure 14: Response spectra for a crack family.

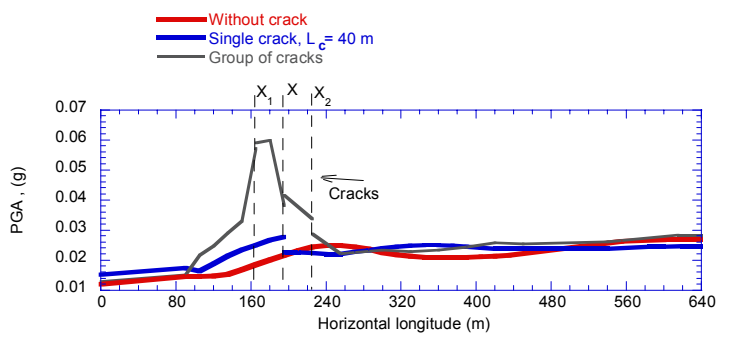

Figure 15: $\quad$ PGA variation over the entire model for a crack family.

\subsection{Effects on adjacent structures}

In order to observe the potential effect that a crack may have in the seismic response of nearby structures, a hypothetical six story building was considered located at several distances, D, 15, 30, 90, 150 and $300 \mathrm{~m}$ away from the crack, towards the left (Figure 16). The crack was assumed to be $40 \mathrm{~m}$ long, and inclined $5^{\circ}$ to wards the building. The structure main characteristics including mass, stiffness and damping are also included in Figure 16. The building was modeled as a shear beam (Romo and Barcena [6]). From Figure 17, it can be seen how the structural response increases up to $30 \%$ with respect the case without crack. This important amplification should be taken into account during the design process. 


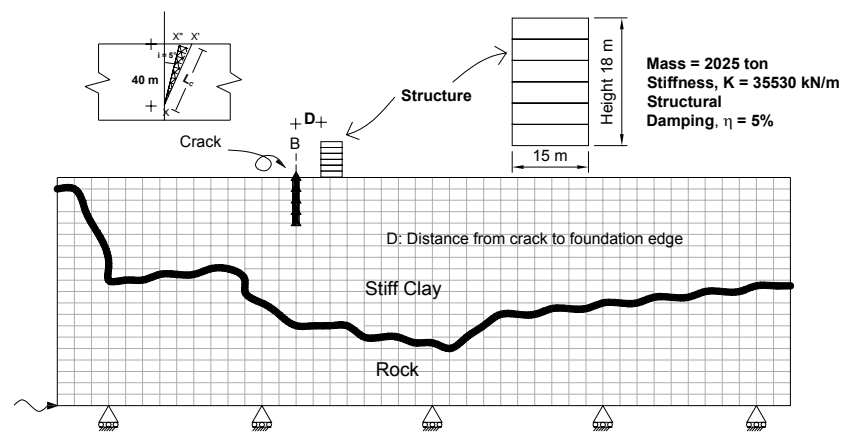

Figure 16: Crack location and schematic representation of adjacent building.

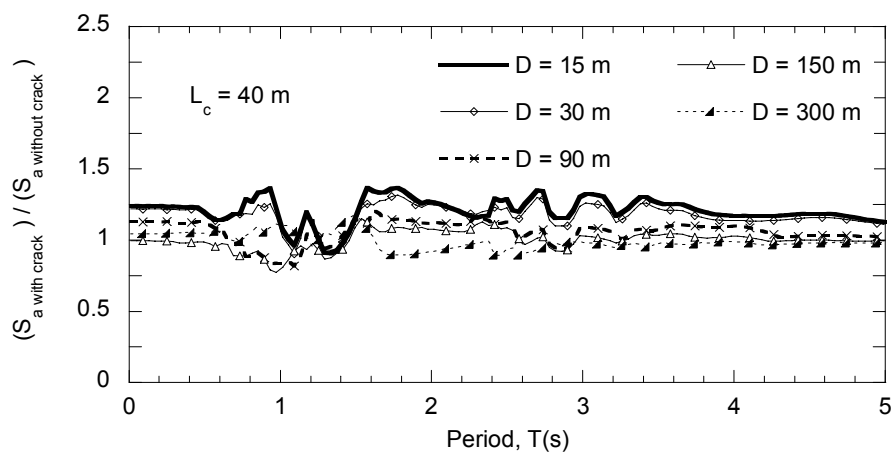

Figure 17: Response spectra computed at the top of the structure.

\section{Conclusions}

Key aspects regarding the seismic response of cracked stiff soils were studied. The most relevant observations drawn from the numerical study included in this paper are as follows. 1) The crack length is the most important factor that affects both spectral amplitudes and frequency content for the free field and structure motions. The presence of the crack causes an out of face response on the ground with respect to that observed in the soil deposit when there is no crack, amplifying or attenuating the surface ground motions and being the source of potential ground motion incoherence. Regarding the effect of the crack at depth, it seems that this completely vanished for depths larger than the crack length, and the cracked media practically follows the un-cracked media motions. 2) For the cases analyzed not significant influence in the soil deposit response was observed as a function of crack inclination, neither in the spectral amplitudes nor the frequency content. 3) The combination of several cracks may increase significantly the PGAs, even up to $200 \%$ and change drastically the frequency content, reducing the predominant period of the soil. 4) Regarding the effect on 
structures, the presence of cracks increase up to $30 \%$ the response computed without crack. All the aforementioned factors should be taken into account when designing structures to be located adjacent to a crack or a crack family.

\section{References}

[1] Itasca Consulting Group. (2005). "FLAC, Fast Lagrangian Analysis of Continua", User's Guide. Minneapolis, Minnesota, USA.

[2] Rojas. E., Romo, M. P., y Saldívar E., (1994). "Un modelo para explicar el agrietamiento de la ciudad de aguascalientes", Memorias de la XVII Reunión Nacional de Mecánica de Suelos, Vol. 1, pp 269-274, Jalapa, November

[3] Schnabel, B., Lysmer, J., y Seed, H.B. 1972. SHAKE. A Computer Program for Earthquake Response Analysis of Horizontally Layered Sites, College of Engineering, University of Berkeley, CA. Rep., No. EERC 7212.

[4] Sun, J., Golesorkhi, R., and Seed, H.B. (1988), "Dynamic modulus and damping ratios for cohesive soils", University of California, Berkeley. Report No. EERC-88/15, EERC

[5] Vucetic, M. and Dobry, R. (1991). "Effect of soil plasticity on cyclic response", Journal of Geotech. Engineering, ASCE, Vol. 114, No. 1

[6] Romo M P and Barcena A. (1994). "Interacción dinámica suelo-estructura en la ciudad de Mexico", Series del Instituto de Ingeniería, UNAM, ISSN 0185-2345, No. 565, December 